\title{
ROKOK ELEKTRONIK DAN SILANG SENGKARUT KOMUNIKASI
}

\author{
Istiqomatul Hayati $^{1 *}$, Reza Helmi ${ }^{2}$, dan Eka Wenats Wuryanta ${ }^{3}$ \\ 1,2,3 Universitas Paramadina Jakarta, Indonesia. \\ *isti.timo@gmail.com
}

\begin{abstract}
E-cigarette consumption increases as smoke-free campaigns worldwide. Some consider the consumption of e-cigarettes is a healthy way to quit smoking. E-cigarettes are considered to help eliminate smoking habit. In fact, quitting smoking cannot be replaced with e-cigarette. Because, in vape there are glycerin, nicotine, and seasoning placed in the cartridge. Honestdoc writes the glycerin or propylene propylene to produce moisture. In effect, an electronic smoker will be irritated to a person's filtration channel. The purpose of this research is to see how Tempo.co and Kompas write news about the difference of communication in the Ministry of Trade and the Ministry of Health who have not published rules regarding the restriction or prohibition of electronic cigarette. Critical discourse analysis used to dissect government communication about electronic cigarette consumption, which isn't in line, such as written Kompas.com and Tempo.co from the start of this issue revolving until now. Both media shows, the government's plainness to publish rules regarding the restriction or prohibition e-cigarettes due to confusion to health of people or save investments. Consequently, until now, there isn't clear regulation about this. Regulations are limited to the new imposition of excise imposed on July 1st 2018.
\end{abstract}

Keyword: Electronic cigarette, restriction, and banning.

\begin{abstract}
Abstrak
Konsumsi rokok elektronik meningkat tajam seiring kampanye bebas asap di seluruh dunia. Sebagian menganggap konsumsi rokok elektronik ini merupakan cara sehat untuk berhenti merokok. Rokok elektronik dianggap membantu menghilangkan kebiasaan merokok. Faktanya, berhenti merokok tidak bisa digantikan dengan merokok elektronik. Sebab, dalam kandungan vape ini terdapat gliserin, nikotin, dan perasa yang diletakkan di cartridge atau alatnya. Honestdoc Editorial Team menuliskan gliserin atau propilen bermanfaat untuk memproduksi uap air. Efeknya, perokok eletronik akan mengalami iritasi pada saluran penapasan seseorang. Tujuan penelitian ini untuk melihat bagaimana Tempo.co dan Kompas menayangkan beritaberita mengenai perbedaan komunikasi di antara para pejabat di Kementerian Perdagangan dan Kementerian Kesehatan yang tidak kunjung menerbitkan aturan mengenai pembatasan atau pelarangan peredaran rokok elektronik. Analisis Wacana Kritis ini dipakai untuk membedah bahasa komunikasi pemerintah dalam mengendalikan konsumsi rokok elektronik, yang tidak sejalan, seperti ditulis Kompas.com dan Tempo. co dari mulai isu ini bergulir pada 2017 hingga sekarang. Kedua media ini menunjukkan, kegamangan pemerintah menerbitkan aturan mengenai pembatasan atau pelarangan rokok elektronik lantaran bingung hendak memenuhi hak kesehatan rakyat atau menyelamatkan investasi. Akibatnya, hingga sekarang, belum ada regulasi yang jelas soal konsumsi ini. Regulasi terbatas pada pengenaan cukai yang baru diberlakukan pada 1 Juli 2018.
\end{abstract}

Kata kunci: rokok elektronik, pembatasan, dan pelarangan.

\section{PENDAHULUAN}

Tingginya pengguna rokok di dunia, membuat WHO terus mendorong masyarakat agar berhenti merokok untuk mengurangi bahaya tembakau dengan berbagai metode, salah satunya adalah menggunakan NRT atau Nicotine Replacement Therapy (terapi pengganti nikotin) (Lam \& West, 2015). NRT adalah metode yang menggunakan suatu media untuk memberikan nikotin yang diperlukan 
oleh perokok tanpa pembakaran tembakau. NRT semula bertujuan untuk menghilangkan pembakaran tembakau dan sebagai sarana alternatif pemberian nikotin. Praktiknya, NRT sering dipakai sebagai alat bantu dalam program berhenti merokok dengan cara menurunkan dosis nikotin secara bertahap (Damayanti, 2016). Ada beragam macam dari NRT, salah satunya adalah rokok elektronik. Rokok elektronik merupakan salah satu NRT yang menggunakan listrik dari tenaga baterai untuk memberikan nikotin dalam bentuk uap dan oleh WHO disebut sebagai electronic nicotine delivery system (ENDS) (Prochaska, 2015)

Rokok elektronik dan perangkat vaping lainnya meningkat popularitasnya di kalangan anak muda dan orang dewasa sejak diperkenalkan di pasar. Peningkatan ini sebagian didorong oleh persepsi publik bahwa vaping tidak berbahaya dibandingkan merokok konvensional. Bahkan penggemar vaping juga berpendapat bahwa perokok konvensional dapat menggunakan cara ini sebagai terapi pengganti nikotin untuk membantu mereka berhenti merokok (Dinardo \& Rome, 2019). Meski rokok elektronik dikatakan bebas asap, faktanya tidak membuatnya benar-benar sehat. Asap vape mengandung nikotin, air, gliserol, propilen glikol, dan pemberi rasa (Reinikovaite, et al., 2018). Nikotin tetap menjadi kandungan utama rokok elektronik, sekalipun ada juga jenis tertentu yang tidak (Palmer \& Brandon, 2018) . Zat nikotin inilah yang menyebabkan pengguna merasakan ketagihan dan sulit berhenti. Honestdoc Editorial Team menuliskan, dalam rokok elektronik, ditemukan kandungan nikotin dengan kadar berbeda mulai dari 0 sampai $100 \mathrm{mg} / \mathrm{ml}$. (Honestdocs Editorial Team, 2019). Selain itu, komponen lain yang terdapat pada vape adalah TSNA. Ini adalah senyawa karsinogen yang ditemukan dalam tembakau. TSNA tidak hadir dalam daun tembakau hijau tetapi terbentuk selama proses nitrosasi (Farsalinos, Gillman, Poulas, \& Voudris, 2015).
Fakta ini makin mengerikan jika mengacu pada laporan VOX, dari Januari sampai 20 November 2019, terdapat lebih dari 2.000 orang terkena sakit paru-paru, bahkan sebanyak 47 orang meninggal dunia di Amerika karena vaping. (Belluz, 2019).

Banyak situs web masih mengklaim bahwa penggunaan rokok elektronik aman karena tembakau tidak terbakar dan karenanya tidak ada inhalasi banyak racun yang ditemukan dalam asap rokok padahal FDA telah melaporkan bahwa kartrid dalam rokok elektrik mengandung nitrosamin, dietilen glikol, dan kontaminan lainnya yang berpotensi berbahaya bagi manusia (Palazzolo, 2013).

Berbahayanya rokok elektronik tidak sekadar kandungan yang ada di dalamnya. Tapi juga saat menggunakannya. Dari 2009 sampai 2016 sudah 195 laporan meledaknya rokok elektronik di Amerika Serikat. Bahkan enam di antara kasus ini terjadi di Colorado dan seluruh korbannya remaja. (Sawaya, 2019). Berbagai data ini tidak membuat pemerintah Indonesia, khususnya Menteri Kesehatan, tersadar untuk membuat regulasi mengenai peredaran rokok elektronik. Kementerian Kesehatan sebenarnya sudah berkali-kali menyuarakan soal pelarangan total konsumsi rokok eletronik. Tapi pergantian rezim membuat kebijakan ini mentah lagi.

Seiringdengansemakingencarnyakampanye mengenai bahaya merokok dan pengurangan perokok di dunia oleh WHO, perusahaan rokok besar dunia mulai bergeser dengan membuat rokok eletronik yang menurut mereka bisa membantu perokok untuk berhenti merokok (Hastan \& Azeharie, 2019). Sebenarnya rokok elektronik sendiri sudah dibuat sejak 1930 (Centers for Disease Control and Prevention, 2016). Bukti adanya rokok elektronik pada tahun tersebut berdasarkan sebuah dokumen berisi hak paten rokok elektronik yang diberikan kepada Joseph Robinson. Namun, rokok tersebut tidak pernah dipasarkan. Salah satu pelopor komputer, Phil Ray bekerja sama dengan Norman Jacobson, seorang ahli fisika. 
Mereka menciptakan rokok eletronik komersial pertama di dunia. Mereka juga melakukan riset mengenai alat penghantar nikotin namun riset mereka gagal tapi berhasil mempopulerkan kata "vape" (V, 2014). Beberapa tahun setelahnya banyak perusahaan ataupun individu melirik industri rokok elektronik, bahkan pada 1998 sebuah perusahaan tembakau di Amerika Serikat mengeluarkan produk yang mirip dengan rokok elektronik dan mengurusnya ke Food and Drug Administration (FDA) untuk dijual ke publik, namun ditolak oleh FDA. Lima tahun kemudian, Hon Lik, seorang ahli farmasi dan perokok, berhasil membuat dan menjual rokok elektrik di bawah perusahaan bernama Golden Dragon Holdings dengan nama Ruyan yang memiliki arti "seperti rokok" (Nayir, Karacabey, Kirca, \& Ozdogan, 2016).

Melihat bahayanya rokok elektronik, dari mulai kandungan hingga cara pemakaian yang membahayakan, media mulai menyuarakannya, termasuk di Indonesia. Hal ini patut disuarakan lantaran rokok elektronik kini makin banyak dikonsumsi oleh anak-anak muda kita. Pemasaran, terutama melalui media sosial, berperan penting dalam mempromosikan rokok elektronik di kalangan remaja, sedangkan toko ritel adalah sumber utama untuk menampilkan rokok elektronik (Perikleous, Steiropoulos, Paraskakis, Constantinidis, \& Nena, 2018).

Organisasi Kesehatan Dunia mengakui kemungkinan bahaya dari ENDS dan merekomendasikan kerangka kerja peraturan yang ketat, Pada 2016, Badan Pengawas Obat-Obatan dan Produk Kesehatan di Inggris berencana untuk melisensikan ENDS sebagai obat-obatan. Adapun Badan Pengawas Obat dan Makanan AS menyelesaikan aturan yang memperluas wewenang pengaturan ENDS (Thurtle, et al., 2016). Indonesia adalah salah satu pasar tembakau terbesar di dunia, yang terkenal dengan rokok kretek (Orlan, Parascandola, \& Grana, 2019). Direktorat Jenderal Pengendalian Penyakit dan Penyehatan Lingkungan (P2PL) Kementerian Kesehatan, Lili Sulistyowati (2016) menuturkan bahwa jumlah seluruh perokok di Indonesia mencapai 90 juta jiwa. Berdasarkan angka tersebut, dapat disimpulkan bahwa rokok merupakan salah satu industri yang sangat berkontribusi bagi pertumbuhan perekonomian di Indonesia (Rahmanto \& Juwitara, 2019). Tapi hingga kini, tak ada aturan yang mengatur soal pembatasan atau pelarangan rokok elektronik, kecuali pengenaan cukai hingga 57 persen pada 2018. Ironisnya, rokok-rokok yang beredar bebas di Indonesia adalah rokok ilegal. Ketiadaan aturan ini membuat rencana persyaratan untuk mengimpor rokok elektronik, harus mengantongi izin dari Kementerian Kesehatan dan Badan POM sekadar jargon semata. Para pengimpor pun tertarik mendapatkan bahan rokok elektronik illegal untuk mendapatkan bahan murah. Yang lebih mengerikan, mengingat rokok elektronik disebut sebagai rokok gaya baru, peminatnya adalah anak-anak muda dan remaja. Mereka menilai rokok ini aman dikonsumsi, dijual bebas di media sosial tanpa ada peraturan melarang atau membatasi, dan harganya murah (Pepper \& Brewer, 2013). Bagi anak muda, vaping bisa meningkatkan kepercayaan diri dan keren (Langley, BellWilliams, Pattinson, Britton, \& Bains, 2019). Adapun orang tua, karena belum ada laporan pembatasan, menilai rokok elektronik tak akan berdampak buruk pada kesehatan.

\section{Project Assistant Tobacco Control Policy} Support in Indonesia-South East Asia, Bigwanto Mouhamad menuliskan, pemerintah menargetkan penurunan prevalensi perokok pada anak di bawah umur 18 tahun dari 7,2 persen pada 2013 menjadi 5,4 persen pada 2019. Faktanya, bukannya terjadi penurunan, prevalensi merokok anak justru naik menjadi 9,1 persen. Laporan Riskesdas 2018 mengungkap fakta bahwa prevalensi pengguna rokok elektronik naik hampir sepuluh kali lipat hanya dalam dua tahun, dari 1,2 persen pada 2016 menjadi 10,9 persen pada 2018. Menurut dia, upaya untuk membuat aturan pembatasan atau pelarangan selalu mentok di Kementerian Perekonomian. 
Sebelumnya, Kementerian Perdagangan pernah berupaya menerbitkan aturan yang mengatur soal penggunaan rokok elektronik. Lembaga ini berpijak pada laporan Badan POM yang menyatakan bahwa rokok elektronik yang beredar di pasaran adalah produk ilegal karena tidak memiliki izin. Kementerian Perdagangan selanjutnya menerbitkan Peraturan Menteri Perdagangan Nomor 86 Tahun 2017 tentang Ketentuan Impor Rokok Elektronik. Isinya mengharuskan importir mendapatkan izin dari Kementerian Kesehatan dan BPOM sebelum memasukkan rokok elektronik ke Indonesia. Sayangnya, peraturan ini tak pernah diterapkan dan ditunda lewat keputusan Menteri Koordinator Bidang Ekonomi lewat surat nomor S-310/M.Eko/II/2017 (Mouhamad, 2019).

Ketiadaan aturan ini diperparah oleh silang sengkarut pernyataan pemerintah yang tidak seia sekata saat membahas soal rokok elektronik. Sementara korban terus berjatuhan, pemerintah abai dengan persoalan ancaman di depan mata saat kita menyosong bonus demografi pada 2020 .

Di media massa, kita disuguhi pernyataan pemerintah yang saling silang, meskipun pada akhirnya dimenangkan pada penyelamatan investasi bukan memprioritaskan kesehatan. Pada persoalan dampak kesehatan, rokok elektronik dianggap aman bagi kesehatan dibandingkan rokok konvensional. Penilaian ini menjadi acuan pemerintah pro investasi untuk tidak segera menerbitkan regulasi yang mengatur pembatasan atau pelarangan peredaran rokok.

Tapi, praktisi Kesehatan tetap menilai rokok elektronik berpengaruh buruk bagi tubuh. Departemen Penyakit Dalam Divisi Respirologi Rumah Sakit Hasan Sadikin (RSHS) Bandung, dr Iceu Dimas Kultsum, SpPD mengatakan, perbedaan rokok elektronik dengan konvensional ada pada kandungan tembakau. Rokok konvensional menggunakan tembakau, tapi tidak pada sebagian jenis rokok elektronik. "Tapi, rokok elektronik mengandung zat lain yang sama berbahaya dengan rokok konvensional," kata Iceu. Ia menjelaskan, dalam sejumlah penelitian disebutkan, rokok elektronink mengandung formaldehida, benzena, dan akrolein. Zat kimia tersebut bersifat karsinogenik yang bisa memicu kanker. (Reni Susanti, 2020).

Isu panas lainnya adalah polisi menemukan kandungan narkoba dalam rokok elektronik. Ketiadaan aturan ini menyebabkan banyak rokok yang beredar diperoleh dari pasar gelap yang tidak dikenakan cukai. Lantaran tidak berpita cukai dan diperoleh di pasar bebas, banyak kandungan di dalam liquid rokok elektronik ini mengandung narkoba. Kondisi ini tak hanya merugikan investasi tapi juga mengancam generasi muda Indonesia yang mengkonsumsi rokok dengan kandungan narkoba.

Perbedaan pendapat itu tidak berujung pada solusi mengeluarkan peraturan pembatasan atau pelarangan sekalian, tapi justru sengaja dibiarkan mengendap dan akhirnya dilupakan. Ada persoalan komunikasi yang dibiarkan berlarut tanpa penyelesaian, kata sepakat, dan tindakan untuk membatasi atau bahkan melarang peredaran rokok elektronik. Akibatnya, rokok elektronik tetap beredar di masyarakat dalam kondisi banyak yang tidak berpita cukai, mengandung narkoba, dan bisa diakses dengan mudah oleh anak-anak.

Analisis wacana bertujuan sebagai suatu analisis untuk membongkar maksud dan arti tertentu. Dalam bukunya, Eriyanto menuliskan pandangan AS Hikam soal tiga pandangan dalam analisis wacana. Pandangan pertama diwakili kelompok positivism-empiris yang melihat bahasa sebagai jembatan antara manusia dan obyek di luar dirinya. Salah satu ciri pemikiran ini adalah memisahkan antara pemikiran dan realitas. Kelompok kedua disebut konstruktivisme, yang banyak dipengaruhi oleh pandangan fenomenologi. Aliran ini menolak pandangan sebelumnya. Artinya, bahasa tidak hanya dilihat sebagai jembatan antara manusia dan obyek di luar dirinya. Sebaliknya, 
konstruktivisme justru menganggap subyek sebagai faktor sentral dalam kegiatan wacana dan hubungan-hubungan sosialnya. Adapun pemikiran berikutnya disebut sebagai pandangan kritis. Kelompok ini ingin mengoreksi pandangan konstruktivisme yang dinilai kurang sensitif pada proses produksi dan reproduksi makna yang terjadi secara historis maupun institusional. Hikam mengatakan analisis wacana digunakan untuk membongkar kuasa yang ada dalam setiap proses bahasa. Pendekatan ini disebut Analasis Wacana Kritis karena memakai perspektif kritis. (Eriyanto, Analisis Wacara Pengantar Analisis Teks Wacana, 2001).

Penelitian-penelitian tentang rokok elektronik sebelumnya selalu mengacu pada bahaya rokok elektronik dilihat dari sisi kesehatannya. Belum pernah ada penelitian yang meneliti soal keterlibatan pemerintah dalam mengatur peredaran rokok elektronik, terutama di Indonesia. Penelitian ini bisa disebut sebagai satu-satunya di Indonesia yang menulis soal keterlibatan pemerintah dan pola komunikasinya untuk membuat regulasi peredaran rokok elektronik. Misalnya pada Electronic Cigarettes and Vaping as a Harm Reduction Alternative: Really yang ditulis oleh Ron Balkisson. (Balkisson, 2019). Penelitian mengungkap bahwa ternyata rokok elektronik itu bukan rokok alternatif dan tidak terbukti lebih sehat dari rokok biasa.

Electronic Cigarettes: Vaping has Unproven Benefits ands Potential Harm ditulis oleh Art Nana dan tim pada 2014 menulis soal ketiadaan bukti bahwa rokok elektronik ini bermanfaat sebagai rokok pengganti. Jurnal ini menunjukkan rokok elektronik menyimpan potensi bahaya bagi kesehatan (DC, A, \& PR, 2014).

Impact of Electronic Cigarettes on the Cardiovascular System ditulis oleh Hanan Qasim dan tim pada 2017. Qasim mengungkap dampak penggunaan rokok elektronik yang sama-sama merusak paru sebagaimana rokok konvensional (Qasim, Karim, Rivera,
Khasawneh, \& Alshbool, 2017)

Marianne W. Jorgensen dan Louise J. Phillips mengemukakan pemikiran Norman Fairclough tentang Analisis Wacana Kritis. Fairclough menggunakan teori yang disingkat dengan AWK ini untuk menguraikan pendekatan yang telah dia kembangkan. Pendekatan Fairclough terdiri atas sederet premis filsafat, metode teoretis, dan teknik-teknik khusus analisis linguistik. Pendekatan Fairclough menyatakan bahwa wacana merupakan bentuk penting praktik sosial yang mereproduksi dan mengubah pengetahuan, identitas, dan hubungan sosial yang mencakup hubungan kekuasaan dan sekaligus dibentuk oleh struktur dan praktik sosial yang lain. Wacana memiliki hubungan dialektik dengan dimensi-dimensi sosial lain yang lain. (Jørgensen \& Phillips, 2002).

Haryatmoko mengungkapkan AWK Fairclough hendak menganalisis bagaimana wacana memproduksi dominasi sosial, mendorong penyalahgunaan kekuasaan suatu kelompok terhadap yang lain dan bagaimana kelompok yang didominasi melalui wacana melawan penyalahgunaan kekuasaan. Wacana sebagai praksis sosial mengarahkan fokusnya untuk menganalisis institusi, organisasi, relasi kelompok, struktur, proses sosial politik untuk dipelajari di tingkat wacana, komunikasi,dan interaksi. Sehingga, AWK mengelaborasi dan menjelaskan hubungan antara kedua lingkup studi termasuk persinggungan lokal dan global: serta struktur wacana dan masyarakat.

Fairclough menuturkan, berangkat dari perhitungan proses semiosis ini, AWK harus mempertimbangkan tiga dimensi, yakni teks, praktik diskursif, dan praksis sosial. Sehingga, dalam menganalisis wacana, yang dilakukan adalah melakukan analisis teks (deskripsi/ mikro), analisis produksi atau interpretasi (meso), dan analisis sosial atau eksplanasi (makro) (Haryatmoko, 2016). Penelitian ini menggunakan teori AWK Fairclough dengan menekankan pada intertekstualitas. Norman Fairclough mengatakan intertekstualitas 
dikembangkan dari pemikiran Julia Kristeva dan Michael Bakhtin. Intertekstualitas adalah sebuah istilah di mana teks dan ungkapan dibentuk oleh teks yang datang sebelumnya, saling menanggapi, dan salah satu bagian dari teks tersebut mengantisipasi lainnya (Fairclough, 1998). Dalam intertekstualitas, kita bisa menemukan sumber adanya ambivalensi dalam teks. Jika teks utama ditentukan atau didasari oleh teks yang lain yang datang lebih dulu, yang masuk dalam komposisi, elemen dari teks utama bisa jadi tidak bisa ditempatkan dalam relasi dengan jaringan intertekstrual dan maknanya bisajadiambivalen, terjadi perbedaan makna. Penelitian ini akan menggunakan pisau intertekstualitas. Dalam penelitian ini kami ingin mencari tahu apa yang menjadi penyebab silang sengkarut komunikasi pemerintah dalam mengatur peredaran rokok elektronik?

Tujuan penelitian ini untuk melihat bagaimana Tempo.co dan Kompas menayangkan berita-berita mengenai perbedaan komunikasi di antara para pejabat di Kementerian Perdagangan dan Kementerian Kesehatan yang tidak kunjung menerbitkan aturan mengenai pembatasan atau pelarangan peredaran rokok elektronik.

\section{METODOLOGI}

Penelitian ini menggunakan analisis kualitatif, yang dilakukan dengan cara deskriptif, untuk memahami fenomena dari subyek penelitian, menyingkap aspek-aspek yang terkandung dalam setiap pernyataan yang keluar dari para pemangku kebijakan, dalam hal ini pemerintah. Teks yang diteliti adalah yang dimuat di Tempo.co dan Kompas. com. Paradigma riset yang digunakan adalah analisis kritis dengan menggunakan Analisis Wacana Kritis versi Norman Fairclough, yakni dengan meneliti analisis teksnya ( representasi, relasi, dan identitas), bagaimana discourse practicenya, serta apa socio cultural practicenya.

Tahapan penelitian dengan mencocokkan pernyataan atau teks yang keluar daripemerintah dengan berbagai teori dan berbagai jurnal mengenai rokok elektronik, dan kabar terkini mengenai kronologi dan kasus-kasus rokok elektronik yang diberitakan di media massa. Selanjutnya penelitian ditindaklanjuti dengan melihat dapur Newsroom di Tempo Media Group dan Kelompok Kompas Gramedia, untuk mengetahui bagaimana teks itu diproduksi serta mengulik sikap redaksi dua media itu terhadap konsumsi rokok dan turunannya. Tahap berikutnya adalah wawancara kepada para pemangku kebijakan atau pejabat di pemerintahan yang menangani perkara rokok elektronik. Wawancara dimaksudkan untuk mendudukkan persoalan sebenarnya apa sehingga aturan tentang pembatasan peredaran rokok elektronik tak kunjung dibuat.

\section{HASIL DAN PEMBAHASAN}

\section{Representasi}

Pada 21 November 2019 Kompas.com menayangkan berita bahwa Menteri Kesehatan Terawan Agus Putranto di Istana Kepresiden Jakarta, menyatakan tidak mau menjustifikasi bahwa rokok eletronik berbahaya bagi kesehatan dan karenanya harus dilarang. Menurut dia, untuk sesuatu yang belum jelas seharusnya jangan dijustifikasi kalau belum ada penelitian komprehensif.

Terawan mengatakan, dampak kesehatan dari pemakaian rokok elektrik sejauh ini memang belum diketahui. Sebab, memang belum ada penelitian komprehensif yang dilakukan. Oleh karena itu, ia tidak mau berkomentar lebih jauh soal bahaya rokok elektrik untuk kesehatan.

Ia pun menyatakan belum berencana melakukan penelitian mengenai dampak kesehatan terhadap konsumen rokok eletronik (Ihsanuddin, 2019).

Sehari kemudian, seakan menjawab
pernyataan Menteri Agus, Tempo.co
memberitakan bahwa pemerintah sudah
seharusnya melarang peredaran rokok
elektronik. Pernyataan ini diungkapkan oleh


Direktur Eksekutif Lentera Anak Indonesia Lisda Sundari yang menerima laporan dari para guru yang kebingungan untuk menindak siswa-siswanya yang membawa rokok elektronik ke sekolah. Para guru merasa tidak memiliki otoritas untuk merazia anak didiknya. Penyebabnya, tidak ada larangan yang menyertai peredaran rokok elektronik itu dan berdalih dengan vaping, mereka justru mengurangi ketergantungan dari rokok konvensional.

Bagi Lisda, pernyataan pemerintah ini aneh. Musababnya, sebagai Menteri Kesehatan yang memiliki otoritas, Terawan berhak membuat peraturan untuk melindungi kesehatan masyarakat. "Ada orang tua melapor anak-anak mengaku tidak merokok (rokok konvensional) tapi merokok rokok elekronik dan dibilang tidak bahaya. Informasi tidak clear. Masak harus nunggu korban dulu baru dibikin peraturan." (Hayati, 2019)

Pro-kontra itu berkaitan dengan desakan masyarakatagar pemerintah segera menerbitkan peraturan untuk membatasi peredaran rokok elektrinik terutama yang tidak bercukai dan mencantumkan seperangkat aturan mengenai konsumsi rokok elektronik. Faktanya, rokok elektronik yang banyak beredar di masyarakat justru yang tidak bercukai. Karena tidak bercukai, kandugan liquid di dalamnya tidak diketahui apakah mengandung bahan berbahaya atau tidak.

Pernyataan Menteri Kesehatan bahwa rokok elektronik belum terbukti berbahaya, penulis menemukan ada keengganan pemerintah yang diwakili menteri kesehatan untuk bersungguhsungguh mengatur peredaran rokok elektronik, apakah akan dilarang atau dibatasi. Apalagi diikuti kalimat selanjutnya, ia belum berencana melakukan penelitian terhadap dampak kesehatan yang diakibatkan dari konsumsi rokok elektronik. Menteri Terawan tak menganggap penting peraturan ini.

Bukan hanya enggan menjustifikasi mengenai rokok elektronik yang berbahaya bagi kesehatan, Terawan menyatakan ia masih mau menunggu pemerintah merancang peraturan soal tembakau alternatif. Menurut Terawan hingga sekarang belum ada aturan yang jelas mengenai rokok elektronik. (Ihsanuddin, 2019). Kalimat Terawan masih menunggu pemerintah merancang peraturan ini dengan alasan belum ada aturan yang jelas mengenai rokok elektronik sungguh pernyataan yang rancu. Sebagai menteri kesehatan yang bertugas menjamin hak kesehatan warga negara, dia berhak mengeluarkan peraturan kesehatan yang mengatur soal rokok elektronik.

Sebenarnya pernyataan Terawan ini mematahkan semangat pro-kesehatan yang dilontarkan oleh Menteri Perdagangan Enggartiasto Lukito pada Kabinet Kerja. Di Kompas.com pada 18 November 2017, Menteri Enggartiasto menyatakan rokok elektronik boleh beredar jika mendapatkan rekomendasi dari Menkes, BPOM, Menperin, dan mendapatkan SNI. Enggar menuturkan alasan peredaran rokok elektronik harus diatur lantaran terindikasi kandungan narkoba di dalamnya.

"Siapa yang tahu isinya ganja atau bukan. Di negara maju itu malah lebih ekstrim dilarang," tutur dia. (Fauzi, Ini Syarat Mendag agar Rokok Elektrik Bisa Beredar di Indonesia, 2017). Dari artikel ini, Kompas ingin menunjukkan ada masalah di antara dua kementerian. Kendati Enggartiasto adalah Menteri Perdagangan yang mengejar investasi, tapi ia memperjuangkan perlunya pengaturan peredaran rokok elektronik setelah melihat produk alternatif ini terindikasi narkoba. Anehnya, Terawan sebagai menteri kesehatan, justru mementahkannya setelah pergantian kabinet.

Artikel di Tempo.co pada 24 September 2019 meminta pemerintah harus tegas mengatur rokok elektronik. Artikel ini mengutip pernyataan Sekretaris Jenderal Perhimpunan Dokter Penyakit Dalam Indonesia (PAPDI), Eka Ginanjar yang mendukung upaya pemerintah agar membuat kebijakan yang tegas dalam mengatur peredaran rokok elektronik. 
Eka mengatakan sejak 2015 hampir dua per tiga negara-negara di dunia sudah memiliki aturan tentang rokok elektronik. Di banyak negara, rokok elektronik memang masih diperdebatkan karena banyak potensi konflik. Aturan tentang pengendalian tembakau di masing-masing negara juga berbeda-beda. (Widiyarti, 2019)

\section{Relasi}

Mengapa pemerintah terkesan enggan untuk segera menerbitkan aturan pembatasan? Artikel di Tempo.co yang tayang pada 27 Januari 2018 ini bisa memberikan gambaran mengenai tarik menarik di antara kelompok pro kesehatan dan pro investasi. Dalam laporan itu, Asosiasi Vape Indonesia menyatakan penetapan tarif cukai untuk cairan rokok elektronik yang dipatok 57 persen terlalu tinggi. Kebijakan itu dinilai memberatkan pelaku usaha rokok elektronik.

Ketua Bidang Legal dan Business Development APVI Dendy Dwiputra mengatakan usaha di bidang rokok elektrik belum sebesar rokok tembakau. Usaha yang berkembang masih berkategori mikro, kecil, dan menengah (UMKM). "Jangan samakan kami dengan rokok konvensional,” katanya. (Florentin, 2018)

Artikel yang dimuat di Kompas.com pada 22 Maret 2019 ini juga bisa memberikan gambaran bagaimana pemerintah memang berharap mendapatkan pemasukan dari cukai rokok elektronik. Pada artikel itu disebutkan pemerintah menargetkan penerimaan negara hingga $\mathrm{Rp} 2$ triliun dari industri rokok elektronik pada 2019, setelah cukai untuk cairan atau liquid ini diterapkan.

Kepala Seksi Tarif Cukai dan Harga Dasar 2 DJBC AGus Wibowo di Jakarta, Jumat (22/3/2019), mengatakan, besarnya target tersebut lantaran potensi dari industri rokok elektrik di Indonesia juga cukup besar. Dia menjelaskan, tahun lalu, 3 bulan setelah pemberian izin perdana berupa Nomor Pokok Pengusaha Barang Kena Cukai (NPPBKC) ke beberapa pengusaha pabrik liquid vape, penerimaan negara dari industri rokok elektrik mencapai Rp 105,6 miliar. Sementara, hingga hari ini, DJBC telah memasangkan pita cukai ke cairan rokok sebanyak 188 miliar buah. (Fauzia, Pengguna Rokok Elektrik Bertambah Pemerintah Berharap Bisa Kutip Cukai Rp 2 T, 2019).

Artikel di Tempo.co pada 25 Juni 2019 ini makin menunjukkan ketidaksinkronan di antara pemerintah sendiri. Badan Narkotika Nasional menemukan kandungan narkoba di dalam liquid rokok elektronik yang diimpor. BNN berada di kubu Badan POM dan Kementerian Kesehatan yang berharap ada aturan yang melarang peredaran rokok elektronik terutama yang ilegal.

Kepala Pusat Laboratorium Narkotika Badan Narkotika Nasional (BNN) Brigadir Jenderal Mufti Djusnir mengatakan, pengguna rokok elektronik berpotensi menyalahgunakan narkoba. "Di dalam liquid vape yang diserahkan ke kami, terkandung 5-Fluoro $A D B$, 5-Fluoro-MDBD-PICA, Cannabidiol, FUB AMB, dan tetrahydrocannabinol," kata Mufti. (Hayati, Ada Narkoba di Dalam Rokok Elektronik, 2019).

\section{Identitas}

Tempo merupakan perusahaan media yang menjunjung tinggi perlindungan dan pemenuhan hak asasi manusia. Di dalam HAM, juga terdapat pemenuhan hak atas seseorang atas kesehatannya. Dalam pengendalian tembakau dan produk turunannya, bagian redaksi Tempo jelas menyatakan keberpihakannya pada pemenuhan kesehatan. Penulis adalah wartawan Tempo yang mengetahui seluk beluk kebijakan redaksi.

Majalah Tempo pada Oktober 2009 menurunkan investigasi soal hilangnya ayat tembakau dalam Undang-Undang Kesehatan yang sudah disahkan sebulan sebelumnya. Laporan investigasi menggegerkan nasional lantaran ada ayat dalam Pasal 113 yang 
mengatur pengamanan zat adiktif itu tiba-tiba lenyap saat disahkan menjadi undang-undang. Pelakunya diduga seorang wakil rakyat bekerja sama dengan industri rokok berdasarkan dukungan partainya kepada wong cilik.

Pada 22 dan 23 September 2015, Koran Tempo juga membuka tabir penyelundupan ayat kretek oleh anggota DPR dalam Rancangan Undang-undang Kebudayaan. Laporan utama yang menjadi headline Koran Tempo dua hari berturut-turut ini membuat Wakil Presiden Jusuf Kalla meminta agar draft RUU Kebudayaan didrop.

Tidak bisa dipungkiri, terkadang sikap redaksi berbeda dengan iklan. Account Executive atau iklan Tempo masih menerima iklan rokok baik untuk penerbitan majalah, koran, dan onlinenya. Tapi, perusahaan sudah membagi jelas antara redaksi dan iklan, saling tidak bersinggungan demi menjaga independensi wartawan dan marwah Tempo sebagai perusahaan media yang menjunjung tinggi kode etik jurnalistik. Sebagai salah satu buktinya, tak lama setelah liputan investigasi ayat rokok yang dihilangkan hasil persekutuan industri rokok dan anggota DPR, kesepakatan iklan sebesar Rp 300 juta yang dijanjikan salah satu pabrikan rokok batal.

Begitu juga dengan Kompas. Perusahaan ini memberikan keberpihakan kepada pemenuhan kesehatan rakyat. Koran Kompas gencar mengkampanyekan pengendalian tembakau dan produk turunannya. Gencarnya pemberitaan tentang pemenuhan hak Kesehatan rakyat membuat redaksi Kompas sepakat menurunkan liputan khusus berhari-hari tentang pengendalian tembakau dan harapan generasi emas yang terbit pada 2018 yang membuat industri rokok marah.

Menurut Adhitya Ramadhan, wartawan Kompas yang kerap memberitakan tentang pengendalian tembakau, begitu laporan hari pertama turun, perusahaan mendapatkan ancaman tentang kesepakatan iklan senilai $\mathrm{Rp}$ 4 miliar menguap. Redaksi Kompas memilih bergeming dengan ancaman itu.

\section{Discourse Practice}

Teks dibentuk lewat praktik diskursus yang akan menentukan bagaimana teks tersebut diproduksi (Eriyanto, p. 316). Sidang redaksi di Tempo.co dan Kompas.com menunjukkan bagaimana teks ini diproduksi.

Meskipun redaksi sepakat untuk pro kesehatan, tak bisa dielakkan ada perbedaan pendapat mengenai wacana pengendalian tembakau dan produk turunannya. Dalam rapat redaksi yang digelar secara online, ada diskusi yang amat tajam antara penulis dan kelompok pengguna rokok elektronik. Pengguna rokok elektronik ngotot agar Tempo.co menurunkan tulisan tentang 'kebaikan' rokok elektronik. Saat perdebatan yang memanas melalui pesan di Whatsapp Group itu, penulis didukung oleh redaksi lainnya, bahwa sikap Tempo untuk pengendalian produk tembakau dan turunannya sudah jelas. Ini, misalnya tercermin pada laporan tentang berbahayanya semua rokok elektronik yang tayang pada 1 Maret 2020.

"Rokok elektronik ini juga tak aman bagi perokok pasif sebab uap rokok elektrik ini menghasilkan aerosol yang mengandung nikotin dan zat kimia lain. Selain mengandung aerosol, uap rokok elektronikjuga mengandung nikotin dengan berbagai kadar, mengandung partikel halus, dan bahan toksik lain, seperti formaldehida, acetaldehida, metal, ditilen glisol, dan tembakau karsinogenik spesifik nitrosamin. Bahan mengandung toksik tersebut berpotensi menyebabkan kanker." (Yayuk Widiarti, 2020)

\section{Sociocultural Practice}

Bagaimana sociocultural practice menentukan teks? Fairclough mengatakan, hubungan itu bukan langsung tetapi dimediasi oleh discourse practice. Metode yang digunakan adalah dari studi pustaka dan penelusuran. (Eriyanto, 2001, p. 321). Jika kita melihat bagaimana Tempo.co dan Kompas.com gencar menggiatkan desakan agar pemerintah untuk menerbitkan aturan mengenai peredaran 
rokok elektronik, hal ini berangkat dari aturan pelarangan serupa di negara lain.

Di Amerika Serikat, sebagai pusat produsen rokok elektronik, beberapa negara bagian sudah melarangnya. San Fransisco yang berada di negara bagian California, menjadi kota pertama di Amerika Serikat yang melarang penjualan rokok elektronik. Padahal, San Fransisco merupakan daerah pusat produksi Juul Labs, produsen rokok elektronik paling populer di AmerikaSerikat (Fauzia, 2019).

Aktivis anti-vaping yang mendukung peraturan ini menyatakan, perusahaan produsen rokok elektrik sengaja menyasar generasi muda dengan menawarkan produkproduk dengan rasa yang beragam. Para kritikus mengatakan bahwa investigasi ilmiah tidak hanya berdampak pada dampak kesehatan yang diperlukan, vaping dapat mendorong kaum muda untuk beralih ke rokok.

Laporan di Kompas pada 20 September 2019 menyebutkan, ada sembilan negara yang sudah menyatakan melarang penjualan rokok elektronik. Australia menjadi negara pertama yang melarang kepemilikan dan penjualan rokok elektronik pada 2009 diikuti Yordania, Hong Kong, dan Kanada. Pada 2010, kebijakan pelarangan ini juga diikuti Arab Saudi dan Singapura. Setahun berikutnya, giliran Belanda, Argentina, dan Venezuela yang memuat kebijakan pemilikan dan pelarangan rokok elektronik ini.

Sanksi terberat yang akan dikeluarkan bagi warga yang kedapatan memiliki atau menjual rokok elektrik adalah denda sebesar 100.000 dollar Hongkong dan penjara dua tahun. Larangan itu dikeluarkan untuk mengurangi risiko berbahaya yang ditimbulkan rokok. (Dzulfaroh, 2019).

Berkorelasi dengan gamangnya pemerintah menerbitkan aturan pembatasan atau pelarangan rokok elektronik, penulis melakukan wawancara dengan para pejabat di Kementerian Kesehatan. Dikisahkan oleh pejabat eselon di kementerian itu, Menteri Terawan menggelar rapat internal dengan jajarannya saat mengawali tahun baru 2020. Saat itu ia menyatakan bahwa rokok elektronik itu lebih baik dari rokok konvensional.

"Pak Menteri bilang, rokok elektronik itu less harmful, ini bahasa Industri Tembakau banget," ujarnya. Kata bahasa industri tembakau yang disebut pejabat itu untuk menjelaskan kecurigaannya bahwa atasannya sendiri dipengaruhi oleh kampanye industri rokok elektronik yang ingin menciptakan bebas asap atau smoke free dengan merokok alternatif.

Dengan kapasitasnya sebagai dokter dan menteri kesehatan, pernyataan bahwa rokok elektronik itu less harmful amat menyesatkan dan bisa memancing lebih banyak pengguna rokok elektronik. Dalam relasi kuasa, jelas sudah Menteri Terawan yang berkuasa. Apapun pernyataan anak buahnya, selama seorang menteri sebagai bawahan Presiden berbicara berbeda, maka usulan di bawahnya pun akan mentah. Pernyataan Menkes ini juga tak sejalan dengan desakan berbagai pihak untuk membatasi peredaran rokok elektronik yang sudah mengemuka sejak 2017. Menteri Perdagangan Enggartiasto Lukito seperti disebut di atas juga sudah menyatakan hendak melarang penjualan rokok elektronik kecuali mendapatkan rekomendasi dari Kementerian Perdagangan, Kementerian Kesehatan, dan Badan POM.

Menteri Enggartiasto sendiri mengatakan ia sudah menandatangani Peraturan Menteri Perdagangan terkait pengawasan rokok elektronik. Tapi surat itu akhirnya terbentur di Kementerian Koordinator Perekonomian, seperti tertulis di Pendahuluan.

Faktanya, seorang sumber yang amat kompeten dalam penanganan rokok elektronik di Badan Pengawasan Obat dan Makanan menerangkan, hingga sekarang belum ada peraturan apapun yang berkaitan dengan rokok ini. Dari hasil wawancara kami melalui telepon, sumber itu menjelaskan, meski sudah ditandatangani, peraturan itu gugur di meja Kementerian Perokonomian. "Katanya ini tak boleh diundangkan karena menghambat 
investasi," ujarnya pada 31 Desember 2019.

Sumber itu juga mengatakan, Badan POM mulai meneliti zat yang terkandung pada rokok elektronik itu sejak 2015. Setelah mengetahui kandungan yang berbahaya, termasuk zat psikotropika kelas 1, lembaga ini membuat policy paper untuk meminta perhatian pemerintah. Selanjutnya, Badan POM menggelar Focus Group Discussion yang melibatkan Kementerian Perekonomian, Kementerian Perdagangan, Kementerian Industri, Badan Nasional Narkotika, Kementerian Kesehatan, dan Bea dan Cukai. Badan POM dan Badan Nasional Narkotika sepakat untuk merekomendasi pelarangan. Dari sinilah muncul desakan untuk mengeluarkan peraturan yang membatasi peredaran rokok elektronik. Saat itu, kata sumber tersebut, ada kegamangan di Kementerian Perdagangan, lembaga yang memiliki otoritas paling tinggi untuk menerbitkan pelarangan konsumsi rokok elektronik. Mereka memikirkan investasi yang tinggi.

Seorang pejabat eselon tiga di Kementerian Kesehatan memberikan informasi baru terkait dengan silang sengkarut aturan itu. Menurut pejabat ini, Menteri Terawan meminta jajarannya hanya memfokuskan tiga program saja,

"Pak Menteri memaksakan hanya boleh memfokuskan tiga hal, yakni stunting, BPJS, dan pengadaan obat-obataan," kata sumber tersebut. Sumber tersebut menjelaskan, mereka kesulitan menyampaikan bahayanya rokok elektronik dan perlunya Kementerian Kesehatan mengeluarkan aturan itu. "Pak Menteri tidak percaya kami, apapun usulan kami langsung dimentahkan, ibaratnya baru berbicara satu kata, dia langsung menyahut dengan tiga kata, sehingga kami kesulitan mau menjalankan program.”

Alih-alih mengatur peredaran rokok elektronik, Kementerian Kesehatan seperti lumpuh untuk mengontrolnya. Praktis, staf seperti kehilangan induknya untuk menjalankan program. Padahal, pemerintah harus segera mengatasi peredaran rokok elektroik itu. Dari laporan Kajian tenang Rokok Elektronik di Indonesi yang dilansir Badan Pengawas Obat dan Makanan pada 2015 menyatakan sebagian besar produk rokok elektronik mengandung nikotin. Food and Drug Administration Amerika Serikat melaporkan bahwa cartridge diklaim tanpa nikotin namun kenyataan menngandung nikotin. Di Prancis dilakukan riset terhadap 20 sampel cartridge. Ditemukan bahwa kandungan nikotin lebih besar 2 hingga 5 kali lipaat dibandingkan dari labelnya. (Direktorat Pengawasan Narkotika, Psikotropika, dan Zat Adiktif, 2015).

Strategi Perusahaan Phillip Morris Intenational adalah untuk mengurangi tiga perokok lebih cepat perokok dari WHO. Setidaknya 40 juta orng pada 2018 beralih ke produk bebas asap. Mereka optimistis pada 2025 perokok rokok konvensional akan berkurang 55 juta dan akan beralih ke produk bebas asap. (International, 2018). Jika dilihat pada situs resmi Philip Moris International yakni pmi.com/sustainability/sustainabilityreport, tampak jelas 'kebaikan' mereka dengan menginisiasi rokok tanpa asap. "Sebagai perusahaan tembakau, kami memiliki tanggung jawab khusus dalam hal keberlanjutan. Kami berusaha untuk terus meningkatkan keberlanjutan bisnis kami dan berkontribusi pada agenda keberlanjutan global.”

Ketua Badan Khusus Pengendalian Tembakau Ikatan Ahli Kesehatan Masyarakat Indonesia (IAKMI), Widyastuti Soerojo mengatakan saat ini, raksasa perusahaan rokok dunia mulai mengembangkan untuk memproduksi rokok elektronik. Tujuannya untuk mendukung cita-cita Badan Kesehatan Dunia (WHO) membuat dunia yang bebas asap. Soerojo menunjukkan BAT meluncurkan produk rokok elektronik dengan merek Vype dan Glo, Philip Morris International menjual produk IQOS, dan PMI-Altria membuat Juul. (Soerojo, 2019). Negara-negara luar sendiri menangkap pesan kampanye bebas asap oleh produsen rokok elektronik ini sebenarnya 
hanya strategi jualan saja. Pada kenyataannya, dampak dan risiko yang mereka terima, sama besar dengan rokok konvensional: sama-sama mengancam kesehatan warga mereka sendiri.

\section{SIMPULAN}

Berdasarkan Analisis Wacana Kritis Fairclough di atas, maka dapat disimpulkan pemerintah gamang bahkan terkesan enggan untuk segera menerbitkan peraturan yang mengatur peredaran rokok elektronik. Para pejabat pemerintah itu, terutama yang dipertontonkan di level menteri lebih suka saling berbantah yang pada ujungnya memperlambat terbitnya aturan. Inilah yang mendorong Tempo.co dan Kompas. com sebagai media untuk memainkan peran sebagai anjing penjaga pemerintah, terus enyalak untuk segera menerbitkan aturannya demi melindungi anak-anak muda. Aturan itu nanti akan membuat anak-anak kesulitan untuk menjangkau rokok elektronik karena harganya mahal dan mempersulit akses mereka untuk mendapatkan dengan persyaratan usia dan tidak dijual bebas di media sosial. Selain itu, aturan itu bisa memperketat masuknya rokok elektronik illegal dan dikhawatirkan mengandung narkoba.

Media dan masyarakat harus berkolaborasi untuk mendesakkan pemerintah agar lebih peduli kepada pemenuhan hak kesehatan rakyat dan tidak mempertontonkan silang pendapat untuk menutupi keengganan melindungi rakyatnya sendiri.

\section{DAFTAR PUSTAKA}

Ariefana, P. (2019, November 21). Menkes Tak Mau Komentari Vape: Belum Ada Aturannya. Retrieved from Suara.com: https://www.suara.com/ news/2019/11/22/095111/menkestak-mau-komentari-vape-belum-adaaturannya

Balkisson, R. (2019). Electronic Cigaettes and Vaping as a Harm Reduction
Alternativel Really? Journal of the COPD Foundation, 281-291. doi:10.15326/jcopdf.6.3.2019.0143

Belluz, J. (2019, 11 22). Vaping is still safer than smoking. That message is getting dangerously muddled. Retrieved from Vox: https://www.vox. com/2019/11/22/20977418/vapinglung-disease-ban-public-health

Budiardjo, M. (2001). Dasar-dasar Ilmu Politik. Jakarta: PT Gramedia Pustaka.

Centers for Disease Control and Prevention. (2016). E-Cigarette Use Among Youth and Young Adults. Atlanta: Centers for Disease Control and Prevention.

Damayanti, A. (2016). Penggunaan Rokok Elektronik di Komunitas Personal Vaporizer Surabaya. Jurnal Berkala Epidemiologi, 250-261. doi:http://dx.doi.org/10.20473/jbe. V4I22016.250-261

DC, L., A, N., \& PR, E. (2014). Electronic Cigarettes: Vaping has Unproven Benefits and Potential Harm. Official Joural of the Asian Pacific Society of Respirology, 945-947. doi:10.1111/ resp. 12374

Dinardo, P., \& Rome, E. S. (2019). Vaping: The new wave of nicotine addiction. Cleveland Clinic Journal of Medicine, 789-798. doi:https://doi.org/10.3949/ ccjm.86a.19118

Direktorat Pengawasan Narkotika, Psikotropika, dan Zat Adiktif . (2015). Kajian tentang Rokok Elektronik di Indonesia. Jakarta : Badan POM RI.

Dzulfaroh, A. N. (2019, September 20). Di 9 Negara Ini, Vape Dilarang! Retrieved Januari 14, 2020, from Kompas: https://www.kompas.com/ tren/read/2019/09/20/165610565/di-9negara-ini-vape-dilarang?page $=$ all

Eriyanto. (2001). Analisis Wacana Pengantar Analisis Media. Yogyakarta: LKiS.

Fairclough, N. (1998). Discourse 
Representation in Media Discourse. New York: Longman.

Farsalinos, K. E., Gillman, G., Poulas, K., \& Voudris, V. (2015). Tobacco-Specific Nitrosamines in Electronic Cigarettes: Comparison between Liquid and Aerosol Levels. International Journal Environmental Research and Public Health, 9046-9053. doi:doi:10.3390/ ijerph120809046

Fauzi, A. (2017, November 18). Ini Syarat Mendag agar Rokok Elektrik Bisa Beredar di Indonesia. Retrieved from Kompas.com: https://ekonomi.kompas. com/read/2017/11/18/160800126/inisyarat-mendag-agar-rokok-elektrikbisa-beredar-di-indonesia

Fauzi, A. (2017, 11 18). Ini Syarat Mendag Agar Rokok Elektrik Bisa Beredar di Indonesia. Retrieved from Kompas: https://ekonomi.kompas.com/ $\mathrm{read} / 2017 / 11 / 18 / 160800126 /$ ini-syaratmendag-agar-rokok-elektrik-bisaberedar-di-indonesia

Fauzi, A., \& Djumena, E. (2017, November 18). Ini Syarat Mendag agar Rokok Elektrik Bisa Beredar di Indonesia. Retrieved from Kompas. com: https://ekonomi.kompas.com/ $\mathrm{read} / 2017 / 11 / 18 / 160800126 /$ ini-syaratmendag-agar-rokok-elektrik-bisaberedar-di-indonesia

Fauzia, M. (2019, Maret 22). Pengguna Rokok Elektrik Bertambah Pemerintah Berharap Bisa Kutip Cukai Rp $2 T$. Retrieved from Kompas. com: https://money.kompas.com/ $\mathrm{read} / 2019 / 03 / 22 / 190900026 /$ pengguna-rokok-elektrik-bertambahpemerintah-berharap-bisa-kutip-cukairp-2-t

Fauzia, M. (2019, Juni 26). San Fransisco Jadi Kota Pertama di AS yang Larang Penjualan Rokok Elektrik. Retrieved from Kompas.com: https://money.kompas.com/ $\mathrm{read} / 2019 / 06 / 26 / 211400226 / \mathrm{san}-$ fransisco-jadi-kota-pertama-di-asyang-larang-penjualan-rokok-elektrik

Florentin, V. (2018, Januari 27). Asosiasi Vape Minta Tarif Cukai Rokok Elektrik Diturunkan. Retrieved from Tempo.co: https://bisnis.tempo.co/read/1054689/ asosiasi-vape-minta-tarif-cukai-rokokelektrik-diturunkan

Haryatmoko. (2016). Critical Discourse Analysis (Analisis Wacana Kritis) Landasan Teori Metodologi dan Penerapan. In Haryatmoko, Critical Discourse Analysis (Analisis Wacana Kritis) Landasan Teori, Metodologi dan Penerapan (p. 24). Jakarta : Rajawali Press.

Hastan, A. A., \& Azeharie, S. S. (2019). Vaping Sebagai Bagian Dari Budaya Populer (Studi Gaya Hidup pada Perempuan Berhijab Pengguna Vape di Komunitas @hijabvapersindonesia).Koneksi,226232. doi:10.24912/kn.v2i2.3889

Hayati, I. (2019, Juni 25). Ada Narkoba di Dalam Rokok Elektronik. Retrieved from Tempo.co: https://gaya.tempo.co/ $\mathrm{read} / 1218178 /$ ada-narkoba-di-dalamrokok-elektronik/full\&view $=\mathrm{ok}$

Hayati, I. (2019, November 22). Pemerintah Seharusnya Larang Rokok Elektronik. Retrieved from Tempo.co: https://gaya. tempo.co/read/1275554/pemerintahseharusnya-larang-rokok-elektronik

Hidayat, A. (2019, 03 22). Jumlah Pengguna Rokok Elektrik Diprediksi Bertambah 1 Juta Orang Tahun Ini. Retrieved from Kontan : https://industri.kontan.co.id/ news/jumlah-pengguna-rokok-elektrikdiprediksi-bertambah-satu-juta-orangtahun-ini

Honestdocs Editorial Team. (2019, 12 20). Kandungan Vape dan Dampaknya pada Tubuh. Retrieved from Honestdocs: https://www.honestdocs.id/kandungan- 
vape-dan-dampaknya-pada-tubuh Ihsanuddin.(2019,1121).Menkes Siap Tampung Aspirasi Publik soal Pro-Kontra Rokok Elektrik. Retrieved Desember 23, 2019, from Kompas: https://nasional.kompas. $\mathrm{com} / \mathrm{read} / 2019 / 11 / 21 / 22183581 /$ menkes-siap-tampung-aspirasi-publiksoal-pro-kontra-rokok-elektrik

International, P. M. (2018). Sustainability Report 2018. New York: Phillip Morris International .

Irianto, R. P. (2019, Oktober 5). Kemenkes Setop Vape sampai Dinyatakan Aman. Retrieved from Mediaindonesia.com: https://mediaindonesia.com/read/ detail/263590-kemenkes-setop-vapesampai-dinyatakan-aman

Irianto, R. P. (2019, Oktober 5). Kemenkes: Setop Vape Sampai Dinyatakan Aman. Retrieved from Mediaindonesia.com: https://mediaindonesia.com/read/ detail/263590-kemenkes-setop-vapesampai-dinyatakan-aman

Irianto, R. P. (2019, September 18). Menkes Nilai Penggunaan Vape Dapat Merusak Kesehatan. Retrieved from Mediaindonesia. com: https://mediaindonesia.com/ $\mathrm{read} /$ detail/260230-menkes-nilaipenggunaan-vape-dapat-merusakkesehatan

Jørgensen, M., \& Phillips, L. J. (2002). Discourse Analysis as Theory and Method. Roskilde: Sage Publications.

Kresna, M. (2018, April 9). Di Balik Alasan IDI Memecat Dokter Terawan. Retrieved from Tirto: https://tirto.id/di-balikalasan-idi-memecat-dokter-terawan$\mathrm{cHrA}$

Lam, C., \& West, A. (2015). Are electronic nicotine delivery systems an effective smoking cessation tool? Canadian Journal of Respiratory Theraphy, 9398.

Langley, T., Bell-Williams, R., Pattinson,
J., Britton, J., \& Bains, M. (2019). 'I Felt Welcomed in Like They're a Little Family in There, I Felt Like I Was Joining a Team or Something': Vape Shop Customers' Experiences of E-Cigarette Use, Vape Shops and the Vaping Community. Environmental Research and Public Health. doi:https:// doi.org/10.3390/ijerph16132341

Mouhamad, B. (2019, Oktober 29). Jebakan Rokok Elektronik. Retrieved Januari 9, 2020, from Detik: https://news.detik. com/kolom/d-4764140/jebakan-rokokelektronik

Mulin, G. (2019, Agustus 30). Vape Horror Teen Left in Coma After Developing Lung DIsease from Vaping Everyday for Three Years. Retrieved Januari 6, 2020, from The Sun: https://www.thesun. co.uk/news/9826814/teen-coma-lungdisease-vaping/

Nayir, E., Karacabey, B., Kirca, O., \& Ozdogan, M. (2016). Electronic cigarette (e-cigarette). Journal of Oncological Science, 16-20. doi:https:// doi.org/10.1016/j.jons.2016.04.001

Orlan, E. N., Parascandola, M., \& Grana, R. (2019). JUUL from the USA to Indonesia: implications for expansion to LMICs. Tobacco Control. doi:10.1136/ tobaccocontrol-2019-054979

Palazzolo, D. (2013). Electronic Cigarettes and Vaping: A New Challenge in Clinical Medicine and Public Health. A Literature Review. Frontiers in Public Health, 2-20. doi:10.3389/ fpubh.2013.00056

Palmer, A., \& Brandon, T. (2018). How do electronic cigarettes affect cravings to smoke or vape? Parsing the influences of nicotine and expectancies using the balanced-placebo design. Journal of Consulting and Clinical Psychology, 486-491. doi:https://doi.org/10.1037/ ccp0000303 
Pepper, J. K., \& Brewer, N. T. (2013). Electronic nicotine delivery system (electronic cigarette) awareness, use, reactions and beliefs: a systematic review. Tobacco Control, 375-384. doi:10.1136/ tobaccocontrol-2013-051122

Perikleous, E. P., Steiropoulos, P., Paraskakis, E., Constantinidis, T. C., \& Nena, E. (2018). E-Cigarette Use Among Adolescents: An Overview of the Literature and Future Perspectives. Frontiers in Public Health, 1-9. doi:10.3389/fpubh.2018.00086

Phillips, M. J. (2007). Analisis Wacana Teori. Yogyakarta: Pustaka Pelajar.

Phillips, M. W. (2007). Analisis Wacana Teori \& Metode. In M. W. Phillips, Analisis Wacana Teori \& Metode (p. 126). Yogyakarta: Pustaka Pelajar.

Prochaska, J. J. (2015). Nicotine Replacement Therapy as a Maintenance Treatment. JAMA， 718-719. doi:10.1001/ jama.2015.7460

Qasim, H., Karim, Z. A., Rivera, J. O., Khasawneh, F. T., \& Alshbool, F. Z. (2017). Impact of Electronic Cigarettes on the Cardiovascular System. Journal of the American Heart Association, 125-139. doi:https://doi.org/10.1161/ JAHA.117.006353

Rachman, F. F. (2017, November 6). Mendag Mulai Awasi Peredaran Rokok Elektrik. Retrieved Januari 6, 2020, from Detik: https://finance.detik.com/ industri/d-3715715/mendag-mulaiawasi-peredaran-rokok-elektrik

Rahayu, A. C. (2019, November 10). Kemenko PMK: Regulasi Vape Ditargetkan Rampung Akhir 2020 . Retrieved from Kontan : https://nasional.kontan.co.id/ news/kemenko-pmk-regulasi-vapeditargetkan-rampung-akhir-2020

Rahmanto, B. T., \& Juwitara, T. (2019). Faktor Psikologi dan Keputusan Pembelian Rokok Elektrik (vape).
Jurnal Manajemen dan Akuntansi, 144-151. doi:https://doi.org/10.32534/ jv.v14i1.727

Redaksi. (2017, November 1). Mendag Akan Larang Peredaran Rokok Elektronik. Retrieved Januari 10, 2020, from Kumparan: https://kumparan.com/ kumparanbisnis/mendag-akan-larangperedaran-rokok-elektrik

Reinikovaite, V., Rodriguez, I. E., Karoor, V., Rau, A., Trinh, B. B., Deleyiannis, F. W.-B., \& Stewart, L. T. (2018). The effects of electronic cigarette vapour on the lung: direct comparison to tobacco smoke. European Respiratory Journal. doi:https://doi. org/10.1183/13993003.01661-2017

Reni Susanti, G. K. (2020, Januari 17). Menyelisik Pro Kontra Dampak Vape untuk Kesehatan. Retrieved from Kompas.com: https://lifestyle.kompas. $\mathrm{com} / \mathrm{read} / 2020 / 01 / 17 / 144701220 /$ menyelisik-pro-kontra-dampak-vapeuntuk-kesehatan?page $=$ all

Sawaya, M. (2019, Januari 25). Dangers of Devective E-Ciggaretes: Why do Vape Pens Explode? Retrieved Januari 6, 2020, from the Sawaya Law Firm: https://www.sawayalaw.com/blog/ vape-pens-explosions/

Soerojo, W. (2019). Benarkah Industri Rokok Sudah Berbalik Arah Menuju Dunia Bebas Melalui Pesan Bebas Asap Rokok? IAKMI/SEATCA Press Briefing (p. 16). Jakarta: IAKMI/SEATCA.

Stein, L. (2019, November 18). Philip Morris Kicks off International Effort to Promote a Smoke-Free Future. Retrieved Januari 14, 2020, from Campaignlive. co.uk: https://www.campaignlive. co.uk/article/philip-morris-kicks-offinternational-effort-promote-smokefree-future/1666103

Sukmana, Y. (2018, 01 27). Industri Vape: Kenapa Industri Rokok Meski Takut? 
Kami Bukan Musuh.. Retrieved from Kompas: https://nasional.kompas.com/ $\mathrm{read} / 2018 / 01 / 27 / 18444151 /$ industrivape-kenapa-industri-rokok-meskitakut-kami-bukan-musuh

Team Direktorat Pengawasan Narkotika, P. d. (2015). Kajian Tentang Rokok Elektronik di Indonesia. Jakarta: Badan POM.

Thurtle, N., Abouchedid, R., Archer, J., Ho, J., Yamamoto, T., Dargan, P., \& Wood, D. (2016). Prevalence of Use of Electronic Nicotine Delivery Systems (ENDS) to Vape Recreational Drugs by Club Patrons in South London. Journal of Medical Toxicology, 61-65. doi:10.1007/s13181-016-0583-3

Tim, C. I. (2019, 11 12). Negara-negara di Dunia yang Melarang Vape. Retrieved from CNN Indonesia: https://www.cnnindonesia.com/gayahidup/20191112115450-255-447584/ negara-negara-di-dunia-yangmelarang-vape
$\mathrm{V}$, B. (2014). Electronic cigarettes and history. The Lancet, 2204-2205. doi:https://doi. org/10.1016/S0140-6736(14)61074-6

Widiani, R. (2018, 12 23). Siapakah Kelompok Remaja Pengguna Vape di Indonesia? Retrieved from Detikhealth: https://health.detik.com/ berita-detikhealth/d-4356084/siapakahkelompok-remaja-pengguna-vape-diindonesia

Widiyarti, Y. (2019, September 24). Perlunya Ketegasan Pemerintah dalam Mengatur Rokok Elektronik. Retrieved from Tempo.co: https://gaya.tempo. co/read/1251974/perlunya-ketegasanpemerintah-dalam-mengatur-rokokelektronik/full\&view $=$ ok

Yayuk Widiarti, B. I. (2020, Maret 1). Mengenal Macam Rokok Elektrik Semua Sama Berbahaya. Retrieved from Tempo.co: https://gaya.tempo.co/read/1314145/ mengenal-macam-rokok-elektriksemua-sama-berbahaya 